\title{
Early morphological effects in reading: Evidence from parafoveal preview benefit in Hebrew
}

\author{
AVITAL DEUTSCH, RAM FROST, and SHARON PELLEG \\ Hebrew University, Jerusalem, Israel \\ and \\ ALEXANDER POLLATSEK and KEITH RAYNER \\ University of Massachusetts, Amherst, Massachusetts
}

\begin{abstract}
Hebrew words are composed of two interwoven morphemes: a triconsonantal root and a word pattern. We examined the role of the root morpheme in word identification by assessing the benefit of presentation of a parafoveal preview word derived from the same root as a target word. Although the letter information of the preview was not consciously perceived, a preview of a word derived from the same root morpheme as the foveal target word facilitated eye-movement measures of first-pass reading (i.e., first fixation and gaze duration). These results are the first to demonstrate early morphological effects in the context of sentence reading in which no external task is imposed on the reader, and converge with previous findings of morphemic priming in Hebrew using the masked priming paradigm, and morphemic parafoveal preview benefit effects in a single-word identification task.
\end{abstract}

The role of morphological factors in visual word processing has been extensively investigated in the last two decades. The vast majority of studies, however, were based on experimental paradigms in which the recognition of multimorphemic words was assessed when they were presented in isolation. Conclusions about lexical processing that are based solely on single-word identification may not generalize, however, to how words are processed when people actually read text (Rayner \& Pollatsek, 1989). That is, readers do not usually encounter isolated words, and the usual processing of words involves their rapid, on-line integration in both semantic and syntactic structures. This criticism may be particularly relevant with respect to morphological effects, given that the morphological structure of words includes information about their semantic and grammatical properties. Thus, the morphological analysis of an upcoming word during reading may be influenced by the ongoing processing of the sentence context.

In the present study, we assessed morphological effects in word recognition in an experimental setting that ap-

This study was supported by Israel Science Foundation Grant 0322253 to A.D. and R.F. and by U.S. National Institute of Health Grant HD26765 to A.P. and K.R. K.R. was also supported by a Research Scientist Award from the U.S. National Institute of Mental Health (MH01255). We thank Alonit Ranya and Noga Sagiv for extensive assistance in running the experiments, and Kenneth Forster, Wayne Murray, Laurie Feldman, and one anonymous reviewer for helpful comments on an earlier version of the article. Requests for reprints should be sent to A. Deutsch, School of Education, Hebrew University, Mount Scopus, Jerusalem 91905, Israel (e-mail: msavital@mscc.huji.ac.il). proximates natural reading. Our goal stemmed from a comprehensive research program on morphological processing in Hebrew that was based exclusively on recognition tasks using words presented in isolation (Deutsch, Frost, \& Forster, 1998; Deutsch, Frost, Pollatsek, \& Rayner, 2000; Frost, Deutsch, \& Forster, 2000; Frost, Deutsch, Gilboa, Tannenbaum, \& Marslen-Wilson, 2000; Frost, Forster, \& Deutsch, 1997). Most of these studies made use of the masked priming paradigm (Deutsch et al., 1998; Frost, Deutsch, \& Forster, 2000; Frost et al., 1997), although the principal findings were further extended to other single-word experimental procedures, such as crossmodal priming (Frost, Deutsch, Gilboa, et al., 2000) and the assessment of parafoveal preview benefit effects in single-word naming (Deutsch et al., 2000). These paradigms are particularly useful in studying the role of morphological factors in mediating lexical access, as they tap the early processes of word recognition and are relatively free from effects due to strategic processes peculiar to the particular tasks being studied.

The data of these studies have consistently indicated that morphological units serve as an organizing principle of the Hebrew mental lexicon and mediate lexical access. Furthermore, these findings are in line with other results obtained in studies that employed the masked priming paradigm to examine morphological processing in IndoEuropean languages (in Dutch and German: Drews \& Zwitserlood, 1995; in French: Forster \& Azuma, 2000; Rastle, Davis, Marslen-Wilson, \& Tyler, 2000; but see Grainger, Cole, \& Segui, 1991; in English: Masson \& Isaak, 1999). The goal of the present study was to determine whether the 
same morphological effects that have been observed in single-word recognition paradigms employing briefly presented primes can be obtained in a natural context of reading. In this case, the dependent variable used-duration of eye fixations-does not require the imposition of any task other than reading the text for comprehension. Since a parafoveal preview paradigm will be used in our present research, we will describe this procedure in detail below.

\section{Parafoveal Preview Benefit Effects}

A good procedure for monitoring the initial processes of lexical access is to measure preview benefit effects stemming from information extracted from the parafovea (i.e., information that is extracted before the eyes actually land on a target word). A large body of research on eye movements in reading (see Rayner, 1998, for a review) has revealed that the perceptual span from which readers extract information is small but is not restricted to the fixated word, and readers can extract information from the next word or two (i.e., those in the parafovea). The perceptual span was found to be asymmetric, extending more to the right of the fixation point during reading from left to right and more to the left during reading from right to left (Pollatsek, Bolozky, Well, \& Rayner, 1981). This asymmetry is likely due to an attentional shift from the currently fixated word to the following words in the text (Morrison, 1984; Reichle, Pollatsek, Fisher, \& Rayner, 1998). Because there is often a processing benefit for word identification from this parafoveal information when the eyes subsequently fixate the word, it is clear that readers often extract information from a word seen in the parafovea before they fixate it.

This parafoveal preview benefit effect is usually measured using the boundary technique (Rayner, 1975). This technique usually involves a rapid change of a single word during the saccade in which the eyes move to fixate the word. (The display change is triggered when the eyes cross an invisible boundary just prior to the target word.) An important feature of the boundary technique is that readers are virtually always unaware of the display change and are unable to consciously identify the stimulus in the parafovea. In spite of this, the parafoveal information is integrated with the subsequent activation of the foveal word, thereby facilitating its identification (Rayner, McConkie, \& Zola, 1980).

When preview benefit is assessed during sentence reading, the fixation time on a target word is the primary dependent measure. Thus, participants are not required to perform any external task other than naturally reading the text. This procedure has two fundamental advantages in studies of word identification in reading. First, it is based on a natural phenomenon that takes place in reading (i.e., the extraction of information from the parafovea) and, therefore, does not require the introduction of additional experimental procedures such as masking. Second, rather than being based on reaction time to specific tasks that are external to the fundamental process of reading, the dependent variable - fixation duration-registers an inherent element of the reading process.
As has been indicated above, our primary aim in the present study was to examine whether our previous findings of active morphemic processing with the masked priming paradigm extend to sentence reading. We will begin by outlining the special characteristics of Hebrew morphology that are relevant to our investigation and then briefly review the main findings regarding morphological processing obtained under masked priming and parafoveal preview conditions.

\section{Basic Features of Hebrew Derivational Morphology}

In Hebrew, as in other Semitic languages, all verbs and the vast majority of nouns and adjectives consist of two basic derivational morphemes: the root and the word pattern. The root usually consists of three consonants, whereas the word pattern consists either of vowels or of a mixture of vowels and consonants. Whereas the root usually carries the core semantic meaning of the word, the word pattern defines its word class and other grammatical characteristics, such as gender, voice (active or passive), and transitivity. Thus, the specific meaning of a word is determined by the word pattern. It should be noted, however, that even though the word pattern shapes the meaning of the root for any specific word, the exact meaning of a word cannot be unequivocally predicted by considering either of its constituent morphemes (the root and the word pattern) independently. This semantic fuzziness particularly characterizes the more than 100 word patterns in the nominal system. In contrast, the verbal system of modern Hebrew contains only 7 patterns and is better defined semantically (see Deutsch et al., 1998, for a detailed description).

A fundamental feature of the derivational morphology of Semitic languages is the nonconcatenated manner in which these two derivationalmorphemes are interwoven to form words. For example, the root $x b r^{1}$ (meaning "assemble") may intertwine with the nominal pattern $m a_{-} \_\_e t^{2}$ (denoting a nominal feminine form) to form the word maxberet ("notebook") or with the word pattern $t a_{-} i_{-}$ (denoting a nominal masculine form) to form the word taxbir ("syntax"). The same principle applies to conjugations in the verbal system: The root $x b r$ may intertwine with the verbal pattern _ $i_{-} e_{-}$(denoting an active verbal form) to form the word xibber, ${ }^{3}$ a causative transitive form ("he combined"), or with the verbal pattern _ $u_{-}$ $a_{-}$(denoting a passive form) to comprise the word $x u b \bar{b} a r$ ("was combined").

This nonlinear structure often obscures the phonological and orthographic transparency of the two constituent morphemes as two independent units. Furthermore, the position of the root letters and the word-pattern letters within the orthographic sequence of a word is not fixed and depends on the structure of the word pattern. For instance, in the examples above, whereas the root consonants $x b r$ constitute the second, third, and fourth letters within the five-letter word $m x b r t$ (/maxberet/, מחברת ), they constitute the second, third, and fifth letters in the five-letter word txbyr (/taxbir/, תחביר). (Note that in un- 
pointed Hebrew script, which is the common way of writing, the vowel marks are often omitted from print, except for some vowels that are sometimes denoted by "vowel letters," such as the letter "y" [yod, ', which corresponds to the vowel/i/ in the word /taxbir/]. The same "vowel letters" may represent consonants in other contexts.) Thus, there is no spatial consistency that reliably marks the location of the orthographic constituents of each of these morphemes distributed in a nonconcatenated manner. As a result, a demonstration of morphological decomposition during lexical access in nonconcatenated languages such as Hebrew is especially compelling and provides an interesting contrast with concatenated linear morphologies such as that of English.

\section{Morphological Processing in Hebrew as Evident in Processes of Single-Word Identification: \\ Masked Priming and Parafoveal Preview Benefit}

Our previous experiments that used the masked priming procedure consistently demonstrated a robust priming effect induced by the root. On the basis of these results, we offered a model for lexical organization and lexical access in Hebrew in which all word units, including both nouns and verbs, are connected to root morpheme units. We suggested that the dynamics of the process of lexical access consist of both lexical retrieval of whole words and a mandatory parallel process of extracting and locating the root morphemes. These two processes may occur in parallel and may facilitate each other through bidirectional connections between the word level and the morphemic level. (For a detailed description of the empirical findings constraining this architecture, as well as differences between the nominal and verbal systems with respect to word-pattern morphemes, see Frost et al., 1997, and Deutsch et al., 1998, respectively.)

In the present study, we examined the dynamics of the process of morphological decomposition for words presented in meaningful text by assessing parafoveal preview benefit effects induced by morphological relatedness. The extension of our investigation to parafoveal presentation stems from important similarities in the cognitive processes involved in masked and parafoveal presentation on the one hand, and from interesting differences on the other. First, both masked priming and parafoveal presentations are sensitive to general orthographic form and to the general position of overlapping letters (masked priming: Forster, Davis, Schoknecht, \& Carter, 1987; Humphreys, Evett, \& Quinlan, 1990; preview benefit: Briihl \& Inhoff, 1995; McConkie \& Zola, 1979; Rayner et al., 1980). Second, both procedures seem to be relatively insensitive to semantic effects. This allows one an opportunity to disentangle morphological effects at the form level from simple semantic factors. In general, semantic effects in masked priming seem to be fragile. For example, significant semantic effects under masked presentation were reported by de Groot and Nas (1991) in Dutch and English, by Williams (1994) in French and English (but only for highly related words), by Grainger et al. (1991) in French, by Sereno (1991) in English, and by Perea and Gotor (1997) in Spanish (but only for relatively long exposure durations of 50 and $67 \mathrm{msec}$ ). In contrast, other authors failed to obtain semantic effects in English (e.g., Forster, 1987; Forster et al., 1987) as well as in Hebrew (Frost et al., 1997, Experiment4). This inconsistency in findings notwithstanding, there is marked evidence for morphological effects in masked priming that are independent of semantic relatedness (Forster \& Azuma, 2000; Frost et al., 1997, Experiment 5; Rastle et al., 2000). As for parafoveal presentation, no preview benefit effects were obtained when the preview was semantically related to the target, at least in English (Balota, Pollatsek, \& Rayner, 1985; Inhoff, 1982; Inhoff \& Rayner, 1980; Rayner, Balota, \& Pollatsek, 1986) and in a translation of the target for SpanishEnglish bilinguals(Altarriba, Kambe, Pollatsek, \& Rayner, 2001). Interestingly, only a few studies, all conducted in English, have manipulated morphological factors in the parafovea while measuring preview effects (Inhoff, 1989a; Lima, 1987). These authors did not find any evidence that morphological information extracted from the parafovea facilitated foveal processing of a word (see also Kambe \& Rayner, 2001).

In contrast with the null effects in English, a significant morphological preview benefit effect was found by Deutsch et al. (2000) in a single-word recognition paradigm in Hebrew. In that study, the preview stimulus consisted of the three letters of a root and was replaced by a target word derived from the same root when the participants' eyes crossed an invisible boundary located between the fixation point and the parafoveal preview stimulus. As was observed in masked priming (Frost et al., 1997), naming latencies were facilitated relative to an orthographic control condition, in which the targets were preceded by the root letters. These results suggest that, unlike in English, a morphological effect may be demonstrated in a morphologically rich language such as Hebrew, even in parafoveal processing.

In the present study, we aimed at examining the preview benefit effect induced by the root morpheme in the context of sentence reading, when the root letters in the parafovea were embedded in a derived word different from the target word and had to be extracted from the preview word. Consequently, unlike in Deutsch et al.'s (2000) study, in which the preview stimulus consisted of the three root letters, the root information was spread over various locations throughout the word in the preview. Assuming that the parafoveal preview effects are relatively insensitive to simple semantic relations, a finding of morphological facilitation with root derivations would strongly suggest that the preview word has been decomposed and the root letters extracted from it. Such a demonstration would be especially compelling because, in the nonconcatenated Hebrew morphology, the letters of the root morpheme are spread across the word. A finding of morphological facilitation under these conditions would also exclude the possibility that the preview benefit stems simply from an overlap of contiguous orthographic units and/or common 
letters occurring in the same location in the preview and in the target. Finally, because preview benefit effects tap the very early phases of target processing, a finding of morphologicaleffects with root derivationsusing parafoveal presentation may provide important insight regarding the time course of morphological processing. It would demonstrate that processes of morphological analysis and decomposition occur very early in the reading process (i.e., even before a word is fixated).

The primary dependent variables used for assessing the effects of a morphologically related preview were firstpass reading time measures - namely (1) the duration of the first fixation on the target word and (2) the gaze duration for the target word (i.e., the sum of the durations of all fixations made on a target word from the first time the reader's eyes land on the word until the eyes move to the preceding or following parts of the sentence). We anticipated that if morphological factors do affect early phases of lexical access during sentence reading, these two measures would be affected by morphological factors. Moreover, the duration of the first fixation should be especially sensitive to the earliest phases of word identification (Inhoff, 1984). Two other commonly used measures are total time (i.e., the total time spent on the target, including regressive fixations) and second-pass time (i.e., the time spent rereading the target). Although these measures were also calculated, they are both associated chiefly with later processes of sentence integration. Therefore, our main focus for the effects of a morphologically related preview consists in the first-pass measures.

\section{METHOD}

\section{Participants}

The participants were 30 undergraduate students at the Hebrew University, all native speakers of Hebrew, who participated in the experiment for course credit or payment. All had normal vision or wore corrective lenses.

\section{Stimuli and Design}

Forty-eight target words were used. All targets were nominal forms and were 4-6 letters long. Each target word was paired with three different previews to create the three experimental conditions: identical (the preview was identical to the foveal target), morphologically related (the preview and the target were derivations of the same root), and orthographic control (the preview and the target shared the same number of letters as did those in the morphologically related condition, but the preview was a derivation of a different root). The previews in all conditions were always nominal forms. Both the morphologically related previews and the control previews shared, on average, 3.15 letters with their respective targets, and the shared letters for both conditions always appeared in the same order in the preview and in the target. However, the original position of the common letters and their contiguity was not necessarily preserved, since it is next to impossible to control all of these aspects within each set of stimuli. Words within each triple (i.e., the target and its two nonidentical preview stimuli) were of equal length. ${ }^{4}$ No nonidentical preview had the same initial letter as the target word. All target words were embedded in sentences of 7-10 words, which had a simple structure of subject, predicate, and object. The sentences also included attributive phrases attached to the noun phrases of the subject and the object. Each target word was the object of the sentence and was the fourth or fifth word in the sentence. Target words were never preceded by short function words, in order to minimize the chances that the reader would skip the word preceding the target. Furthermore, the target word was never the last word on a line. Because this was the first experiment in Hebrew in which a preview benefit effect has been assessed in sentences, we attempted to keep the semantic context of the sentences neutral. That is, the targets were consistent with the semantic context of the sentences, but there was no close semantic relation between the target word and any of the preceding words, nor was the target word a highly predictable continuation of the preceding context.

Predictability was controlled through preliminary procedures. The first was a completion task. Twenty-one participants who did not take part in the reading experiment were asked to read the beginning of each of the experimental sentences (i.e., the words preceding the target) and to complete them. Any sentential context that was completed with the actual target word by at least 4 participants was replaced (six sentences were replaced for this reason). The second was a predictability rating procedure, which was implemented after the completion task to ensure that no odd sentences were included. In this procedure, 20 participants who had not participated in the completion task were asked to assess the target's predictability for each of the sentences on a scale of 1 (low) to 7 (high). Only sentences that scored between 3 and 6 were included in the experiment. Since all sentences included in this semantic scoring procedure were reasonable and fairly predictable, another eight sentences of very low predictability were added to the final list as fillers, in order to increase the variability within the list of sentences to be scored.

The sentences were divided into three lists. Each list contained 16 sentences in each of the three experimental conditions. The stimuli were rotated within the three conditions in each list by a Latin square design. Ten participants were tested on each list, allowing each participant to provide data points in each condition, yet avoiding stimulus repetition effects. The stimuli were ordered randomly for each participant. An example of the stimuli used in the experiment is presented in Table 1.

\section{Procedure and Apparatus}

Eye movements were monitored by an SR Research Ltd. (Canada) EyeLink eyetracker. The eyetracker is an infrared video-based tracking system with two cameras (one for each eye) with two infrared LEDs for illuminating each eye mounted on a headband (which weighs $450 \mathrm{~g}$ ). The cameras sample pupil location at $250 \mathrm{~Hz}$. The sentences were presented on a video monitor (EIZO FlexScan F56/T), which was interfaced with a 586 computer, which was interfaced with another 586 computer, which, in turn, was interfaced with the eyetracking system. Although viewing was binocular, only data from the right eye were used for analysis. The spatial resolution of the eyetracking system is less than $.5^{\circ}$. The participants were seated $57 \mathrm{~cm}$ from the video monitor, and 1.8 characters subtended $1^{\circ}$ of visual angle.

The experiment began with nine practice trials, which were immediately followed by the test trials. Each trial started with a fixation point appearing on the right side of the monitor, the location of which coincided with the location of the first letter in the sentence. Once the participant focused on the fixation point, the calibration was verified and the preview screen, which consisted of the complete sentence with one of the three preview words in the target location, was displayed. An invisible boundary was located before the last letter of the word preceding the target word. The participants were instructed to read the sentences for comprehension. When the participants' eyes crossed the invisible boundary, the preview screen was replaced by the target screen, which was identical to the preview screen for all words except the target word (Rayner, 1975). This display change was accomplished within $16 \mathrm{msec}$, and thus always took place during the saccade. The target screen was displayed until the 
Table 1

Examples of Stimuli Used in the Experiment

\begin{tabular}{|c|c|c|c|}
\hline Screen & Identical & $\begin{array}{l}\text { Morphologically } \\
\text { Related }\end{array}$ & Orthographic Control \\
\hline \multirow{3}{*}{ Preview } & Invisible Boundary & Invisible Boundary & Invisible Boundary \\
\hline & המשב המסור בחצ| מסגרת & המשב המסור בחיר הסגרה & המשב המסור בתר נגזרת \\
\hline & הקטן. & הקטן. & הקטן. \\
\hline \multirow{3}{*}{ Target } & $\begin{array}{c}\text { ("The devoted father chose } \\
\text { the frame (/misgeret/)a for } \\
\text { his young child's glasses") } \\
\text { msgrt }^{\mathrm{b}}\end{array}$ & $\begin{array}{l}\text { ("The devoted father chose } \\
\text { the extradition (/hasgara/) } \\
\text { for his young child's glasses") } \\
\text { hsgrh }\end{array}$ & $\begin{array}{l}\text { ("The devoted father chose } \\
\text { derivative (/nigzeret/) for } \\
\text { his young child's glasses") } \\
\text { ngzrt }\end{array}$ \\
\hline & המשקפי המסור בחר מסגרת & המשקפ המסור בחר מסגרת & המשקפ המסור בחר מסגרת \\
\hline & הקטן. & הקטן. & הקטן. \\
\hline
\end{tabular}

participants finished reading the sentence and moved their eyes toward a green square at the bottom of the left side of the screen. Their focusing on the green square signaled the experimenter to bring up the next trial. Twenty-five percent of the sentences were followed by a yes/no question, to ensure that the sentences were being read for meaning. ${ }^{5}$

\section{RESULTS}

All trials in which either the word preceding the target word or the target word itself was skipped were eliminated from the analysis. Cutoff points of 140 and $800 \mathrm{msec}$ were used to eliminate very short and very long single fixations. Four percent of the total observations were excluded on the basis of these criteria. Separate averages were calculated for each participant and each item for each of the following measures: first-fixation duration, gaze duration, total time, and second-pass time. For each of the four measures, outliers more than 2 standard deviations ( $S D \mathrm{~s})$ above the mean (for each participant in each condition) were replaced by the cutoff value, and the mean was recalculated. The means are presented in Table 2.

As is indicated in the table, fixation times for the firstpass measures were longest in the control condition. For all measures except first-fixation duration, fixation time was shortest in the identical condition. Of greatest interest is the 12-msec facilitation in the morphologically related condition relative to the orthographic control condition in the two first-pass measures. There was no significant effect of preview on second-pass time, so that it appeared that virtually the entire effect of the preview occurred in the first pass.

\section{Primary Analyses}

First-fixation duration. One-way analyses of variance (ANOVAs) revealed a significant effect of preview condition for both participant and item analyses $\left[F_{1}(2,58)=\right.$
$8.1, M S_{\mathrm{e}}=197, p<.001$, and $F_{2}(2,94)=6.4, M S_{\mathrm{e}}=405$, $p<.005$, respectively]. Planned comparisons revealed that the first-fixation duration in the identical condition was significantly shorter than that in the orthographic control condition $\left[F_{1}(1,29)=11.7, M S_{\mathrm{e}}=448, p<.005\right.$, and $\left.F_{2}(1,47)=9.5, M S_{\mathrm{e}}=884, p<.005\right]$. Of greatest interest is that the first-fixation duration in the morphologically related condition was significantly shorter than that in the orthographic control condition $\left[F_{1}(1,29)=10.3\right.$, $M S_{\mathrm{e}}=423, p<.005$, and $F_{2}(1,47)=7.0, M S_{\mathrm{e}}=968, p<$ .05 ], and the 1-msec difference between the identical and morphologically related conditions was clearly not significant $\left(F_{\mathrm{S}}<1\right)$.

Gaze duration. There was a significant effect of preview condition for participants $\left[F_{1}(2,58)=6.7, M S_{\mathrm{e}}=\right.$ $526, p<.005]$ and items $\left[F_{2}(2,94)=6.6, M S_{\mathrm{e}}=864, p<\right.$ $.005]$. Planned comparisons revealed that gaze duration in both the identical and morphologically related conditions were significantly shorter than that in the orthographic control condition [identical preview: $F_{1}(1,29)=13.8$, $M S_{\mathrm{e}}=1,026, p<.001$, and $F_{2}(1,47)=11.0, M S_{\mathrm{e}}=$ $2,043, p<.005$; morphological preview: $F_{1}(1,29)=4.4$, $M S_{\mathrm{e}}=1,036, p<.05$, and $F_{2}(1,47)=4.2, M S_{\mathrm{e}}=1,752$, $p<.05$, respectively]. The 10 -msec difference between the identical and the morphologically related conditions was not significant $\left[F_{1}(1,29)=2.4, M S_{\mathrm{e}}=1,096, p=\right.$ $\left..13 ; F_{2}(1,47)=3.0, M S_{\mathrm{e}}=1,389, p=.09\right]$.

Total time. There was a significant effect of preview condition in the item analysis $\left[F_{2}(2,94)=3.8, M S_{\mathrm{e}}=2,724\right.$, $p<.05]$ but not in the participant analysis $\left[F_{1}(2,58)=\right.$ $\left.2.3, M S_{\mathrm{e}}=2,757, p=.1\right]$. Planned comparisons revealed that the preview condition main effect in the item analysis reflects an identical preview effect $\left[F_{2}(1,47)=8.2, M S_{\mathrm{e}}=\right.$ $4,685, p<.01]$. The difference between the morphologically related and orthographic control conditions was not significant $\left(F_{2}<1\right)$. 
Table 2

Mean Latencies (in Milliseconds) and Standard Deviations ( $S D s$ ) of First Fixation, Gaze Duration, Total Time, and Second Pass for the Three Preview Conditions

\begin{tabular}{|c|c|c|c|c|c|c|}
\hline \multirow[b]{2}{*}{ Measure } & \multicolumn{2}{|c|}{ Identical } & \multicolumn{2}{|c|}{$\begin{array}{c}\text { Morphologically } \\
\text { Related }\end{array}$} & \multicolumn{2}{|c|}{$\begin{array}{c}\text { Orthographic } \\
\text { Control }\end{array}$} \\
\hline & Latency & $\overline{S D}$ & Latency & $\overline{S D}$ & Latency & $S D$ \\
\hline First fixation & 225 & 23 & 226 & 31 & 238 & 30 \\
\hline Preview effect & 13 & & 12 & & & \\
\hline Gaze duration & 257 & 38 & 267 & 50 & 279 & 55 \\
\hline Preview effect & 22 & & 12 & & & \\
\hline Total time & 372 & 90 & 393 & 108 & 400 & 92 \\
\hline Preview effect & 28 & & 7 & & & \\
\hline Second pass & 114 & 70 & 126 & 85 & 121 & 63 \\
\hline Preview effect & 7 & & - & & & \\
\hline
\end{tabular}

Second pass. There was no main effect of morphological preview condition in either the participant analysis or the item analysis $\left(F_{\mathrm{S}}<1\right)$.

\section{Additional Analyses}

We carried out additional analyses to eliminate other possible accounts of the data. Specifically, we examined the duration of the fixation prior to the fixation of the target word (fixation $n-1$ ) and the go-past time. The go-past time is the total fixation time from the moment when the reader first fixates the target word until an eye movement is made to a word to the right (or to the left in a right-toleft writing system) of the target word. This measure thus includes cases in which the reader fixates the target word and then makes an immediate regression to an earlier part of the sentence. The time of all fixations made following this regression (and any refixation on the target word prior to movement rightward [or leftward] of it) are added to the initial fixation time on the word. Finally, we also examined a possible confound in the experiment.

Fixation $n-1$ analyses. There are two reasons to examine the duration of the fixation prior to that of the target word. First, it might be possible that, on some fixations when the reader was fixating word $n-1$, attention was allocated to the target word. This might result in a longer fixation $n-1$ in the two nonidentical conditions, since the preview words were anomalous in the sentence context. Second, it might be possible (due to inaccuracy of the eyetracking equipment) that the preview was occasionally fixated (when our equipment perceived the prior word as fixated), and that this produced the difference between the morphemic preview and control preview conditions. That is, it is possible that our apparatus may have counted some fixations that were actually on the target word as not having crossed the boundary yet; then, when the next fixation was made (presumably on the target word), the change was noticed and interference resulted. Both hypotheses predict that there should be appreciable interference on fixation $n-1$ in the two nonidentical preview conditions, because an anomalous word would have been fixated and/or attended to on an appreciable percentage of the trials. However, the duration of fixation $n-1$ (the last fixation prior to boundary crossing) was quite similar for all three preview conditions [identical $=$ $216 \mathrm{msec}$, morphologically related $=222 \mathrm{msec}$, orthographic control $=217 \mathrm{msec} ; F_{1}(2,58)=1.12, p=.33$; $\left.F_{2}(2,94)=1.13, p=.33\right]$. Moreover, the hypothesis that there was a nontrivial number of trials on which people actually fixated the preview word because of miscoding by the equipment predicts that there should have been stronger interference on the following fixation (i.e., the one counted in our first-fixation durations) in each of the nonidentical preview conditions than in the identical preview condition, in which there was no display change. However, first-fixation durations were the same in the identical and morpheme preview conditions.

Go-past analyses. It might be that the reduced firstpass duration for the morphologically related condition does not necessarily reflect easier processing of the target word, but, rather, that processing difficulties are registered by regressions to preceding words in the sentence immediately upon encounter with the target word. However, this analysis (which includes regressions to prior words) revealed the same basic pattern as did the gaze duration analysis (identical $=276 \mathrm{msec}$, morphologically related $=$ $275 \mathrm{msec}$, and orthographic control = $291 \mathrm{msec}$ ). Indeed, the pattern of data is quite similar to that of the firstfixation duration data.

A possible confound. As was indicated above, the sequence and number of letters shared by the nonidentical previews were equated with those of their corresponding targets. However, it was impossible to control for whether the matching was equated letter position by letter position. We think that this kind of confound is extremely unlikely to explain the present pattern of data. First, as was indicated above, the previews in both nonidentical conditions differed from the target in the first letter position. In studies of orthographic overlap, matching this position has been the most crucial factor in achieving orthographic preview benefit (Briihl \& Inhoff, 1995; Inhoff, 1989b; Rayner et al., 1980). In spite of this, the morphological preview condition produced as large a benefit in the firstfixation duration measure as did the identical condition (which had matching initial letters). In addition, we ex- 
amined the data to determine whether failure to control for matching in the second position was likely to produce the advantage in the morphological condition relative to the control condition. In fact, there was little evidence that second-letter overlap (in the absence of first-letter overlap) had any appreciable effect on the preview benefit. For example, for first-fixation duration, the differences between the morphologically related and control conditions were $20 \mathrm{msec}$ for items in which the two preview conditions were matched on second-letter overlap, $12 \mathrm{msec}$ when only the morphemically related preview matched the target, and $20 \mathrm{msec}$ when only the control condition matched the target.

\section{DISCUSSION}

The present study demonstrates a morphological preview benefit effect for Hebrew words that share a root. This morphological preview effect was observed in the context of sentence reading, in which no external task, such as naming aloud or lexical decision, was required. By using previews consisting of words derived from the same roots as the foveal target words rather than overtly presenting the root letters alone, the present study simulated the natural conditions of morpheme extraction as closely as possible, as the morphological information of the root is spread throughout the entire word in the preview. Moreover, the morphological preview benefit effect was observed early in processing, in the two eye-movement measures that reflect first-pass reading-namely, firstfixation duration and gaze duration. In fact, there appeared to be no clear evidence of any additional delayed effects of the preview. That is, the cleanest measure of rereading of the target word is second-pass time, and there was only a suggestion that second-pass time was shorter for the identical condition than for the other two conditions. (Note that the $S D$ s in these conditions were more than half the values of the means.) Because the preview benefit effect in reading reflects such early processes of word identification-extraction of information prior to the initial fixation on the word and its measurement within 200-300 msec of the initial fixation - the overwhelmingly likely locus of our morphemic effect is in the process of identifying words in Hebrew. An interesting outcome of our study is the near identity in the first-fixation duration observed for the identical and morphologically related preview conditions. An advantage of the identical condition over the morphemic preview condition did appear in the gaze duration measure, although it did not reach statistical significance. Thus, in the first-fixation duration measure, which is probably most sensitive to early processes in lexical access, the root seems to be equivalent to the whole word. This supports the hypothesis that the extraction of the root takes place in the earliest phase of word identification and lexical access.

The results in Hebrew contrast with those of previous studies in English, in which no morphological preview effects were observed in sentence reading (Inhoff, 1989a;
Kambe \& Rayner, 2001; Lima, 1987). The contrast in results may reflect linguistic differences between Hebrew and English. Since Hebrew morphology is significantly richer than English morphology (see Plaut \& Gonnerman, 2000 , for a discussion), it is possible that morphological processing can be more easily detected in a language such as Hebrew than in English.

Finally, we should consider an alternative interpretation of the results-namely, that the observed benefit effect was due to simple semantic overlap rather than to morphological relatedness. Our claim that preview benefit reflects morphological factors is based, on the one hand, on the failure to observe semantic effects in Hebrew using the same type of morphological relation in the masked priming paradigm and, on the other hand, on the similarity between the masked priming and preview benefit paradigms. Given that both paradigms produce similar morphemic effects, we posit that the morphological factors that caused the effect in the masked priming (in which semantic factors were controlled) are likely to account for the morphological effect in the present study. Nonetheless, this is only suggestive, and a stronger conclusion would have followed if semantic relatedness had been manipulated directly in the preview experiment.

In sum, the results of the present study are the first to demonstrate evidence of early morphological processes in word identification in Hebrew under experimental paradigms that closely mimic natural reading. Whether our findings reflect only the specific characteristics of Hebrew or can be extended to other languages deserves further investigation. However, the results of our experiment clearly show that morphological decomposition is a basic stage of text processing in Hebrew.

\section{REFERENCES}

Altarriba, J., Kambe, G., Pollatsek, A., \& Rayner, K. (2001). Semantic codes are not used in integrating information across eye fixations in reading: Evidence from fluent Spanish-English bilinguals. Perception \& Psychophysics, 63, 875-890.

Balota, D. A., PollatseK, A., \& Rayner, K. (1985). The interaction of contextual constraints and parafoveal visual information in reading. Cognitive Psychology, 7, 364-390.

BRIIHL, D., \& INHOFF, A. W. (1995). Integrating information across fixations during reading: The use of orthographic bodies and of exterior letters. Journal of Experimental Psychology: Learning, Memory, \& Cognition, 21, 55-67.

DE Groot, A. M., \& NAS, G. L. (1991). Lexical representation of cognates and noncognates in compound bilinguals. Journal of Memory \& Language, 30, 90-123.

Deutsch, A., Frost, R., \& Forster, K. (1998). Verbs and nouns are organized and accessed differently in the mental lexicon: Evidence from Hebrew. Journal of Experimental Psychology: Learning, Memory, \& Cognition, 24, 1238-1255.

Deutsch, A., Frost, R. Pollatsek, A., \& Rayner, K. (2000). Early morphological effects in word recognition in Hebrew: Evidence from parafoveal preview benefit. Language \& Cognitive Processes, 15, 487-506.

Drews, E., \& ZWITSERLOOd, P. (1995). Morphological and orthographic similarity in visual word recognition. Journal of Experimental Psychology: Human Perception \& Performance, 21, 1098-1116.

Forster, K. I. (1987). Form-priming with masked primes: The bestmatch hypothesis. In M. Coltheart (Ed.), Attention and performance XII (pp. 127-146). Hillsdale, NJ: Erlbaum. 
Forster, K. I., \& AzUma, T. (2000). Masked priming for prefixed words with bound stems: Does submit prime permit? Language \& Cognitive Processes, 15, 539-561.

Forster, K. I., Davis, C., SchoKnecht, C., \& CARter, A. (1987). Masked priming with graphemically related forms: Repetition or partial activation? Quarterly Journal of Experimental Psychology, 30, 1-25.

Frost, R., Deutsch, A., \& Forster, K. (2000). Decomposing morphologically complex words in a nonlinear morphology. Journal of Experimental Psychology: Learning, Memory, \& Cognition, 26, 751-765.

Frost, R, Deutsch, A., Gilboa, O., Tannenbaum, M., \& MarslenWilson, W. (2000). Morphological priming: Dissociation of phonological, semantic, and morphological factors. Memory \& Cognition, 28, 1277-1288.

Frost, R, Forster, K. I., \& Deutsch, A. (1997). What can we learn from the morphology of Hebrew? A masked priming investigation of morphological representation. Journal of Experimental Psychology: Learning, Memory, \& Cognition, 23, 829-856.

Grainger, J., Cole, P., \& Segui, J. (1991). Masked morphological priming in visual word recognition. Journal of Memory \& Language, 30, 370-384.

Humphreys, G. W., EvetT, L. J., \& Quinlan, P. T. (1990). Orthographic processing in visual word identification. Cognitive Psychology, 22, 517-560.

InHOFF, A. W. (1982). Parafoveal word perception: A further case against semantic preprocessing. Journal of Experimental Psychology: Human Perception \& Performance, 8, 137-145.

INHOFF, A. W. (1984). Two stages of word processing during eye fixation in the reading of prose. Journal of Verbal Learning \& Verbal Behavior, 23, 612-624.

INHOFF, A. W. (1989a). Lexical access during eye fixations in reading: Are word access codes used to integrate lexical information across interword fixations? Journal of Memory \& Language, 28, 444-461.

InHoff, A. W. (1989b). Parafoveal processing of words and saccade computation during eye fixation in reading. Journal of Experimental Psychology: Human Perception \& Performance, 15, 544-555.

InHoff, A. W., \& RAYNeR, K. (1980). Parafoveal word perception: A case against semantic preprocessing. Perception \& Psychophysics, 27, 457-464.

Kambe, G., \& RAYner, K. (2001, November). Parafoveal versus foveal processing of morphologically complex (prefixed) words. Paper presented at the 42nd Annual Meeting of the Psychonomic Society, Orlando, FL.

Lima, S. D. (1987). Morphological analysis in sentence reading. Journal of Memory \& Language, 26, 84-99.

Masson, M. E. J., \& IsAAK, M. I. (1999). Masked priming of words and nonwords in a naming task: Further evidence for a nonlexical basis for priming. Memory \& Cognition, 27, 399-412.

McConkiE, G. W., \& ZoLA, D. (1979). Is visual information integrated across successive fixations in reading? Perception \& Psychophysics, 25, 221-224.

Morrison, R. E. (1984). Manipulation of stimulus onset delay in reading: Evidence for parallel programming of saccades. Journal of Experimental Psychology: Human Perception \& Performance, 10, 667682.

Perea, M., \& Gotor, A. (1997). Associative and semantic priming ef- fects occur at very short stimulus-onset asynchronies in lexical decision and naming. Cognition, 62, 223-240.

Plaut, D., \& Gonnerman, L. M. (2000). Are non-semantic morphological effects incompatible with a distributed connectionist approach to lexical processing? Language \& Cognitive Processes, 15, 445-485.

Pollatsek, A., Bolozky, S., Well, A. D., \& Rayner, K. (1981). Asymmetries in the perceptual span for Israeli readers. Brain \& Language, 14, 174-180.

Rastle, K., Davis, M., Marslen-Wilson, W., \& Tyler, L. K. (2000). Morphological and semantic effects in visual word recognition: A time-course study. Language \& Cognitive Processes, 15, 507-537.

RAYNER, K. (1975). The perceptual span and peripheral cues in reading. Cognitive Psychology, 7, 65-81.

RAYNER, K. (1998). Eye movements in reading and information processing: 20 years of research. Psychological Bulletin, 124, 372-422.

Rayner, K., Balota, D. A., \& Pollatsek, A. (1986). Against parafoveal semantic preprocessing during eye fixations in reading. Canadian Journal of Psychology, 40, 473-483.

Rayner, K., McConkie, G. W., \& Zola, D. (1980). Integrating information across eye movements. Cognitive Psychology, 12, 206-226.

Rayner, K., \& Pollatsek, A. (1989). The psychology of reading. Englewood Cliffs, NJ: Prentice-Hall.

Reichle, E. D., Pollatsek, A., Fisher, D., \& Rayner, K. (1998). Towards a model of eye movement control in reading. Psychological Review, 105, 125-157.

Sereno, J. A. (1991). Graphemic, associative, and syntactic priming effects at a brief stimulus onset asynchrony in lexical decision and naming. Journal of Experimental Psychology: Learning, Memory, \& Cognition, 17, 459-477.

Williams, J. N. (1994). The relationship between word meanings in the first and second language: Evidence for a common, but restricted, semantic code. European Journal of Cognitive Psychology, 6, 195-220.

\section{NOTES}

1. The letter $x$ stands for the fricative velar phone in Hebrew.

2 . The underscores represent the places where the root's consonants are inserted.

3. The repetition of the letter $b$ (Hebrew bet) represents germination of the second consonant of the root. The germination is marked orthographically only in pointed Hebrew, by a dot in the middle of the consonant.

4. Since no frequency data are available in Hebrew, we could not match the frequencies of the preview stimuli in the three preview conditions. However, it is quite unlikely that frequency affects performance in the preview benefit paradigm, because in many standard preview experiments by Rayner and colleagues (e.g., Rayner \& Pollatsek, 1989), the preview was sometimes a nonword, sometimes a nonword that was orthographically similar to the target word, and sometimes a word that was orthographically similar to the target. These conditions did not yield any differences in performance.

5 . The questions were answered correctly $99 \%$ of the time.

(Manuscript received July 24, 2001; revision accepted for publication April 22, 2002.) 